\title{
Association of smoking or tobacco use with ear diseases among men: a retrospective study
}

Kiran Gaur ${ }^{1,3^{*}}$, Neeraj Kasliwal ${ }^{2}$ and Rajeev Gupta ${ }^{2}$

\begin{abstract}
Background: Health related behaviour specially smoking and tobacco in any form are major determinants of health and lead to health inequities. Tobacco leads to various health problems including ear, nose and throat diseases.
\end{abstract}

Objective: To determine the influence of smoking or tobacco use on ear diseases we performed a retrospective study among men.

Method: Of 11454 subjects of different age-groups there were 4143 men aged 20-60 years who were evaluated for demographic variables, smoking/tobacco use and middle and internal ear diseases. Descriptive statistics and age adjusted logistic regression analyses were performed.

Results: Among the 4143 men, 1739 (42.0\%) were smokers or used tobacco. In smokers/tobacco users compared to non-users the age adjusted odds ratios and $95 \%$ confidence intervals (Cl) for chronic suppurative otitis media were 1.13 (Cl 0.96-1.34), acute otitis media 1.16 (Cl 0.82-1.64), suppurative otitis media 1.21 (Cl 0.79-1.84), otosclerosis $0.97(\mathrm{Cl} 0.52-1.33)(\mathrm{p}>0.05)$ and for overall middle ear diseases was $1.15(\mathrm{Cl} 0.99-1.33, \mathrm{p}=0.05)$. For internal ear diseases the age adjusted odds ratios were for sensorineural hearing loss $1.12(\mathrm{Cl} 0.92-1.58), 0.12(\mathrm{Cl}$ $0.42-0.93)$ for vertigo and tinnitus and overall internal ear diseases were $0.97(\mathrm{Cl} 0.77-1.22, \mathrm{p}=0.81)$. Among men 40-60 years there was a significantly greater risk for both middle ear ( $\mathrm{OR} 1.73, \mathrm{Cl} 1.29-2.30$ ) and internal ear diseases (OR 1.94, Cl 1.24-3.04) $(\mathrm{p}<0.001)$.

Conclusion: Smoking/tobacco use is significantly associated with greater prevalence of middle and internal ear diseases among middle-aged men in India.

\section{Introduction}

The hazardous effect of tobacco on health is universally known[1]. The tobacco-induced negative effects on health include various types of cancers, heart disease, strokes, emphysema, and a slew of other serious (and often fatal) illnesses as observed in epidemiological and clinical studies[1,2]. Evidences have accumulated in recent years on the adverse effects of smoking and tobacco use on ear diseases and hearing among different population groups [3-10]. Some studies, on the other hand, have reported absence of such an association[11-13]. All forms of smoking and tobacco use are harmful $[1,14,15]$ and there are significant data on relationship of smoking and middle-ear diseases in children (by passive smoking) and in adults

\footnotetext{
* Correspondence: kirangaur@rediffmail.com

'Department of Statistics, Banasthali University, Jaipur 302001, India

Full list of author information is available at the end of the article
}

$[3,4]$. Among adults the risks of internal ear diseases especially hearing loss also increases with smoking[5,9]. The risk of becoming hearing-impaired often increases with the number of cigarettes smoked, as well as with the intensity and the duration of exposure to smoke and tobacco [10]. Relationship of non-smoked tobacco use and combined smoking and tobacco use has not been well studied. $[14,15]$

Previous studies have mainly focused on the independent association of smoking on ear diseases and hearing but almost none have evaluated combined effects of smoking and non-smoked tobacco use on different type of ear diseases and hearing[3-15]. We previously reported results of a retrospective study of 30 year trends in various otolaryngorhinological diseases in India[16]. In this study we also collected data on smoking and tobacco use and the present study was undertaken to evaluate the association between these habits and middle and internal

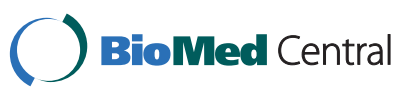

() 2012 Gaur et al; licensee BioMed Central Ltd. This is an Open Access article distributed under the terms of the Creative Commons Attribution License (http://creativecommons.org/licenses/by/2.0), which permits unrestricted use, distribution, and reproduction in any medium, provided the original work is properly cited. 
ear disease in men. Number of female tobacco users was low. The study also aimed to evaluate the role of smoking/tobacco use at different age-groups as it is likely that more prolonged exposure shall lead to greater ear diseases.

\section{Methods}

The study was conducted at a non-government ENT center at Jaipur. From 1975 to 2005, > 125,000 patients of different diseases were evaluated here. We randomly selected patients $(n=11,454)$ at an interval of five years to evaluate disease trends. ${ }^{16}$ For the purpose of the present study we evaluated a sample of 4143 males (as female tobacco users were small in number) aged 20-60 years after exclusion of children where tobacco use or smoking was less. Men who gave history of tobacco smoking (cigarettes, bidis and others) or used nonsmoked tobacco (chewing, snuff, etc.) were considered as tobacco users. Among the smokers/tobacco users were about $50 \%$, isolated tobacco chewing was present in $20 \%$ and the rest both smoked and chewed tobacco. Demographic details were available in the medical records but other details including details of other addictions and risk factors were not available. All the case-files were screened and coded for diagnosis by a senior clinician. The patients were classified according to complaints and clinical examination into major diagnostic groups and disease conditions according to International Classification of Diseases (ICD-9) as reported earlier[16]. The diseases were broadly classified into middle ear and internal ear diseases. The study is approved by ethical committee of Monilek Hospital and Research Centre, Jaipur.

\section{Statistical analyses}

All the data were computerized. Statistical analyses were performed using SPSS program, version 12.0 (SPSS Inc, Chicago). Descriptive statistics are presented. Patients were classified according to their habit of tobacco intake (independent variable, dichotomous) and disease status (dependent variable). Odds ratios and 95\% confidence intervals $(\mathrm{CI})$ were determined using logistic regression analysis. It was a generalized linear model used for binomial regression. Like other forms of regression analysis, it makes use of one or more predictor variables that may be either numerical or categorical. Tobacco intake was considered as independent variable and various middle and internal ear diseases were treated as dependent variable.

$\mathrm{P}$ values $<0.05$ were considered significant.

\section{Results}

In the 11,454 study subjects there were 4143 men aged 20-60 years. Among these 1739 (42.0\%) were smokers or used tobacco. Of these 1054 (60.6\%) belonged to agegroup 20-39 years and 685 (39.4\%) were aged 40-60 years. Tobacco non-users were 2404 and 1751 (72.8\%) were aged 20-39 years and 653 (27.2\%) were in age-group 40-60 years. Eight hundred and sixty seven (49.8\%) tobacco users and 1438 (59.8\%) non-users were residents of urban area and 872 (50.2\%) tobacco users and 966 $(40.2 \%)$ non-users were the residents of semi urban and rural areas.

Among the middle ear diseases chronic suppurative otitis media (CSOM), acute otitis media (AOM), secretory otitis media (SOM) and otosclerosis were found to be the most common with 659 (15.9\%), 136 (3.2\%), 88 (2.1\%) and 41 (0.9\%) patients respectively when adjusted for age. Amongst tobacco users 294 (16.9\%) had CSOM, 62 (3.5\%) had AOM, 41 (2.3\%) had SOM and 17 (0.9\%) had otosclerosis. The age adjusted odds ratio and 95\% CI for tobacco users for CSOM was 1.13 (CI 0.96-1.34), AOM 1.16 (CI 0.82-1.64), SOM 1.21 (CI 0.79-1.84) and for otosclerosis it was 0.97 (CI 0.52-1.82) $(p>0.05)$ (Table 1$)$. The middle ear diseases were present in 920 subjects of which 411 (23.6\%) were tobacco users with odds ratio was 1.15 (CI 0.99-1.33 $p=0.05$ ) (Table 2). For internal ear diseases sensorineural hearing loss (SNHL) and vertigo/tinnitus were the most common diseases. SNHL was observed in $222(5.3 \%)$ patients and among tobacco users were in 103 (5.9\%) men. Vertigo and tinnitus was observed in 117 (2.8\%) subjects and among tobacco users were in 37 (2.1\%). The age adjusted odds ratio was 1.12 (CI 0.92-1.58) for SNHL and 0.12 (CI 0.42-0.93) for vertigo and tinnitus (Table 1). For internal ear disease as whole, we had a sample of 336 males and tobacco use was in 139 (7.9\%). The odds ratio for internal ear disease among tobacco users was $0.97(0.77-1.22, p=0.81)$ (Table 2).

Age specific odds ratios were also calculated to see the effect of age on middle and internal ear diseases. Among middle aged men 40-60 years there was a significantly greater risk for both middle ear (OR 1.73, CI 1.29-2.30) and internal ear diseases (OR 1.94, CI 1.24-3.04) $(p<$ 0.001) (Table 2).

\section{Discussion}

This study reveals that middle-aged tobacco user men had a significantly greater risk for both middle ear and internal ear diseases as compared to those who did not use tobacco. This difference is mainly due to greater prevalence of chronic middle ear diseases and sensorineural hearing loss in this group.

Cruickshanks et al.[5] performed a population based cross sectional study among 3753 subjects (43\% men) in USA to determine association of hearing loss with smoking. There were 54\% smokers and ex-smokers in this group with $40 \%$ smokers reporting $>10$ pack years of smoking. Otological examination and pure-tone audiometery was performed and after adjusting for other risk factors such as age and sex, current smokers were 1.69 
Table 1 The effect of any tobacco use on the development of middle and internal ear

\begin{tabular}{|c|c|c|c|c|c|c|}
\hline & Disease & $\begin{array}{c}\text { Total } \\
(\mathrm{n}=4143)\end{array}$ & $\begin{array}{c}\text { Smoking/Tobacco use } \\
(\mathrm{n}=1739)\end{array}$ & $\begin{array}{l}\text { Non-user } \\
(\mathrm{n}=2404)\end{array}$ & $\begin{array}{l}\text { Odds Ratio } \\
(95 \% \mathrm{Cl})\end{array}$ & $P$ value \\
\hline \multirow[t]{4}{*}{$\begin{array}{l}\text { Middle Ear } \\
\text { Disease }\end{array}$} & $\begin{array}{l}\text { Chronic suppurative otitis } \\
\text { media }\end{array}$ & $659(15.9)$ & $294(16.9)$ & $365(15.1)$ & $1.13(0.96-1.34)$ & 0.13 \\
\hline & Acute otitis media & $136(3.2)$ & $62(3.5)$ & $74(3.0)$ & $1.16(0.82-1.64)$ & 0.38 \\
\hline & Secretory otitis media & $88(2.1)$ & $41(2.3)$ & $47(1.9)$ & $1.21(0.79-1.84)$ & 0.37 \\
\hline & Otosclerosis & $41(0.9)$ & $17(0.9)$ & $24(1.0)$ & $0.97(0.52-1.82)$ & 1.0 \\
\hline \multirow{2}{*}{$\begin{array}{l}\text { Internal Ear } \\
\text { Disease }\end{array}$} & Sensorineural hearing loss & $222(5.3)$ & $103(5.9)$ & $119(4.9)$ & $1.12(0.92-1.58)$ & 0.16 \\
\hline & Vertigo \& tinnitus & $117(2.8)$ & $37(2.1)$ & $80(3.3)$ & $0.12(0.42-0.93)$ & 0.02 \\
\hline
\end{tabular}

All the above values are adjusted for age.

Numbers in parentheses are percent unless specified.

$\mathrm{Cl}$ confidence intervals

times as likely to have hearing loss as compared to nonsmokers (CI 1.31-2.17). The present study shows lower odds ratio of 1.40 (CI 1.07-1.85) which could be due to the lower mean age in the present study. On the other hand, in the age-group corresponding to the US study odds for internal ear diseases are similar (1.94, CI 1.243.04). For middle ear diseases there are very limited data among adults and studies are mainly confined in children that have evaluated harmful effects of second-hand smoke[3,4,17]. Adair-Bischoff et al.[17] reported odds of 1.85 (CI 1.15-2.97) for children exposed to second-hand smoke by $>2$ members of the household. We did not study children and therefore the results are not available. It is also likely that low odds of middle ear diseases (overall odds 1.13, CI $0.97-1.31$ ) as compared to sensorineural hearing loss (overall odds 1.40, CI 1.07-1.85) are due to confounding effects of different type of tobacco usage in the study. Larger studies with better classification of tobacco use are required to confirm the findings of the present study.

Strengths of the study include uniqueness (as this is the only large study from India), representativeness (registry data in an urban clinical practice) and a large sample size. Hearing loss is the most important otological disease related to smoking/tobacco use[1,5] and we also evaluated sensorineural hearing loss using the most reliable technique, pure-tone audiometery, and this is a study strength. We did not study the effects of smoking or non-smoked tobacco use separately as the information related to specific type of tobacco use was not available for these subgroups. Other limitations of this study include retrospective nature and lack of detailed description of amount of tobacco use. We also did not inquire regarding multiple confounders such as exposure to environmental noise, use of betel-quid, pan-masala, alcohol use and other addictions which all can independently influence the middle and internal ear diseases[8-11,15]. We did not also study the influence of tobacco use in women and young children as the absolute numbers were low.

\section{Conclusion}

In conclusion, this study shows a significant association of smoking/tobacco use with hearing loss in middleaged adults and adds to the growing list of diseases attributable to smoking and tobacco use[1]. Smoking and tobacco habit is taking its toll in this country and it has been predicted that in this century it would lead to more than a hundred million premature deaths in the country[18]. National level policy change[19] leading to total cessation of this habit is urgently required.

Table 2 Age-group specific odds-ratio for smoking/tobacco use and ear diseases

\begin{tabular}{cccccc}
\hline Disease & Age-Group & Smoking/tobacco use $(\mathbf{n}=\mathbf{1 7 3 9})$ & Non tobacco user $(\mathbf{n}=\mathbf{2 4 0 4 )}$ & Odds ratio $(\mathbf{9 5} \% \mathbf{C l})$ & $\mathbf{P}$ value \\
\hline Middle Ear & $20-39$ & $267(15.3)$ & $394(16.4)$ & $0.57(0.43-0.77)$ & 0.0 \\
\hline & $40-60$ & $144(8.3)$ & $23(5.1)$ & $1.73(1.29-2.30)$ & 0.0 \\
\cline { 2 - 6 } & Total (Unadjusted) & $411(23.6)$ & $517(21.5)$ & $1.13(0.97-1.31)$ & 0.1 \\
\cline { 2 - 6 } & Total (Age adjusted) & $411(23.6)$ & $509(21.1)$ & $1.15(0.99-1.33)$ & 0.05 \\
\hline Internal Ear & $20-39$ & $50(2.9)$ & $91(3.8)$ & $0.51(0.33-0.81)$ \\
\hline & $40-60$ & $96(5.5)$ & $90(3.7)$ & $1.94(1.24-3.04)$ & 0.0 \\
\cline { 2 - 6 } & Total (Unadjusted) & $146(8.4)$ & $181(7.5)$ & $1.12(0.90-1.41)$ & 0.3 \\
\cline { 2 - 6 } & Total (Age adjusted) & $139(7.9)$ & $197(8.2)$ & $0.97(0.77-1.22)$ \\
\hline
\end{tabular}




\section{Author details}

'Department of Statistics, Banasthali University, Jaipur 302001, India. ${ }^{2}$ Dr KC Kasliwal's ENT Centre, Paanch Batti, Jaipur 302001, India. ${ }^{3} 17$, Luv -Kush Nagar I, Tonk Phatak, Jaipur 302015, India.

\section{Authors' contributions}

KG conceived, designed and implemented the study, provided statistical inputs and wrote the first draft of the manuscript. NK overviewed data collection and checked minor medical details about diseases. RG jointly conceived and designed the study, provided critical academic inputs and wrote the subsequent revision of the manuscript and prepared the final manuscript. All authors read and approved the final manuscript.

\section{Competing interests}

All the authors have no competing interests relevant to this article.

Received: 3 November 2011 Accepted: 3 April 2012

Published: 3 April 2012

\section{References}

1. Shafey O, Eriksen M, Ross H, Mackay J: The Tobacco Atlas. 3 edition. Atlanta: American Cancer Society; 2009.

2. Bartecchi CE, Mackenzie TD, Schrier RW: The human costs of tobacco use1. N Engl J Med 1994, 330:907-912.

3. Adair-Bischoff CE, Sauve RS, Kimberley B, Brant R: Smoking and middle ear disease. Otolaryngol Head Neck Surg 1996, 114:837-840.

4. Aligne CA, Stoddard JJ: Tobacco and children. Arch Paediatr Adolesc Med 1997, 151:648-653

5. Cruickshanks KJ, Klein R, Klein BE, Wiley TL, Nondahl DM, Tweed TS: Cigarette smoking and hearing loss: the epidemiology of hearing loss study. JAMA 1998, 279:1715-1719.

6. Starck J, Toppila E, Pyykko I: Smoking as a risk factor in sensory neural hearing loss among workers exposed to occupational noise. Acta Otolaryngol 1999, 119:302-305.

7. Nakanishi N, Okamoto M, Nakamura K, Suzuki K, Tatara K: Cigarette smoking and risk for hearing impairment: a longitudinal study in Japanese male office workers. J Occup Environ Med 2000, 42:1045-1049.

8. Siegelaub AB, Friedman GD, Kedar A, Seltzer CC: Hearing loss in adults. Relation to age, sex, exposure to load noise, and cigarette smoking. Arch Environ Health 1974, 29:107-109.

9. Friedman $G D$, Siegeland $A B$, Seltzer $C C$ : Cigarette smoking and exposure to occupational hazards. Am J Epidemiol 1969, 98:175-183.

10. Virokannas $H$, Anttonen $H$ : Dose-response relationship between smoking and impairment of hearing acuity in workers exposed to noise. Scand Audiol 1995, 24:211-216.

11. Barone JA, Peters JM, Garabrant DH, Bernstein L, Krebsbach R: Smoking as a risk factor in noise-induced hearing loss. J Occup Med 1987, 29:741-745.

12. Brant LJ, Gordon-Salant S, Pearson JD, Klein LL, Morrell CH, Metter EJ, Fozard JL: Risk factors related to age-associated hearing loss in the speech frequencies. J Am Acad Audiol 1996, 7:152-160.

13. Karlsmose $B$, Lauritzen $T$, Engberg $M$, Parving $A$ : A five-year longitudinal study of hearing in a Danish rural population aged 31-50 years. Br J Audiol 2000, 24:47-55.

14. Boffetta P, Hecht S, Gray N, Gupta P, Straif K: Smokeless tobacco and cancer. Lancet Oncol 2008, 9:667-675.

15. Reddy KS, Gupta PC: Tobacco control in India New Delhi: Government of India, Ministry of Health; 2004.

16. Gaur K, Kasliwal N, Bhandari A, Amisha B, Gupta VP, Gupta R: Changing trends in otorhinolaryngological diseases at a non-government clinic at Jaipur. Ind I Otolaryngol Head Neck Surg 2009, 61:173-178.

17. Adair-Bischoff CE, Sauve RS: Environmental tobacco smoke and middle ear disease in preschool-age children. Arch Pediatr Adolesc Med 1998, 152:127-133.

18. Jha P, Jacob B, Gajalakshmi V, Gupta PC, Dhingra N, Kumar R, Sinha DN, Dikshit RP, Parida DK, Kamadod R, Boreham J, Peto R: For the RGI-CGHR Investigators: A nationally representative case-control study of smoking and death in India. N Engl J Med 2008, 358:1137-1147.

19. Beaglehole R, Ebrahim S, Reddy S, Voute J, Leeder S: Chronic disease action group. Prevention of chronic diseases: a call to action. Lancet 2007, 370:2152-2157. doi:10.1186/1617-9625-10-4

Cite this article as: Gaur et al:: Association of smoking or tobacco use with ear diseases among men: a retrospective study. Tobacco Induced Diseases 2012 10:4.

\section{Submit your next manuscript to BioMed Central and take full advantage of:}

- Convenient online submission

- Thorough peer review

- No space constraints or color figure charges

- Immediate publication on acceptance

- Inclusion in PubMed, CAS, Scopus and Google Scholar

- Research which is freely available for redistribution 